\title{
Affect Dynamics Across the Lifespan: With Age, Heart Rate Reacts Less Strongly, but Recovers More Slowly From Unpleasant Emotional Situations
}

\author{
Cornelia Wrzus and Viktor Müller \\ Max Planck Institute for Human Development, \\ Berlin, Germany
}

\author{
Gert G. Wagner \\ German Institute for Economic Research, Berlin, Germany, and \\ Max Planck Institute for Human Development, Berlin, Germany
}

\author{
Ulman Lindenberger and Michaela Riediger \\ Max Planck Institute for Human Development, Berlin, Germany
}

\begin{abstract}
We propose that a comprehensive understanding of age differences in affective responses to emotional situations requires the distinction of 2 components of affect dynamics: reactivity, the deviation from a person's baseline, and recovery, the return to this baseline. The present study demonstrates the utility of this approach with a focus on age differences in responses of negative affect and heart rate to an unpleasant emotional situation in 92 participants aged 14 to 83 . The emotional situation was elicited with a social-cognitive stress task. Participants' negative affect and heart rate were measured throughout the task. Results showed that heart rate reactivity decreased, but heart rate recovery time increased, with age. In contrast, no significant age differences were observed in either reactivity or recovery for negative affect. These findings confirm that reactivity to, and recovery from, unpleasant emotional situations are distinct components of affect dynamics. They underscore the multidirectional nature of age differences in affective processes.
\end{abstract}

Keywords: heart rate reactivity, recovery, coherence, affect regulation, stress

Unpleasant incidents make some people very annoyed, but bother others less strongly. In addition, some people take a long time to cool down again, whereas others get back to normal quickly. We propose that both reactivity and recovery are distinct processes of affect dynamics - the flux of affective states over time - that also vary by age. Our aim in this article is to demonstrate that this differentiation contributes to a better understanding of age differences in affect from adolescence to old age. To meet this aim, we investigated age differences in reactivity to, and recovery from, an unpleasant emotional situation by measuring both negative affect and heart rate. The findings are relevant both to researchers interested in affective states in general and researchers interested specifically in stress.

Cornelia Wrzus and Viktor Müller, Max Planck Institute for Human Development, Berlin, Germany; Gert G. Wagner, German Institute for Economic Research, Berlin, Germany, and Max Planck Institute for Human Development; Ulman Lindenberger and Michaela Riediger, Max Planck Institute for Human Development.

This research was funded by the German Federal Ministry for Education and Research (Grants 01UW0706 and MPI001) and by the Max Planck Society. We thank Annette Brose and Kathrin Klipker for their valuable comments on earlier versions. We are grateful to Julia Delius for medical advice on participants' medication and for editorial assistance.

Correspondence concerning this article should be addressed to Cornelia Wrzus, Max Planck Institute for Human Development, Lentzeallee 94, 14195 Berlin, Germany. E-mail: wrzus@mpib-berlin.mpg.de
The model of strength and vulnerability integration (SAVI) proposes factors that influence age differences in affective well-being (Charles, 2010; Charles \& Luong, 2013). Regarding strengths, people are assumed to get better at regulating their affective states as they get older (Charles, 2010; Charles \& Luong, 2013; Scheibe \& BlanchardFields, 2010). Improved affect regulation should result from previous life experiences and motivational changes to maintain well-being (Carstensen \& Charles, 1998; Charles, 2010; Riediger, Schmiedek, Wagner, \& Lindenberger, 2009). Regarding vulnerabilities, people are assumed to become less physiologically resilient (Charles, 2010; Charles \& Luong, 2013; Uchino, Birmingham, \& Berg, 2010). For example, general physical health declines and some components of the cardiovascular system become less flexible and less robust as people age (Ferrari, Radaelli, \& Centola, 2003; Steinhagen-Thiessen \& Borchelt, 1999). Resulting from the acquired strengths and vulnerabilities, affective well-being is assumed to be more stable and better with older age as long as the emotional situation does not overtax the individual's limited resources; within these limits, reactivity to emotional situations should be less pronounced with older age. Yet when emotional situations exceed the available resources, high levels of distress, and/or of physiological arousal, are assumed to occur and to be more pronounced with older age (Charles \& Luong, 2013; Labouvie-Vief, Gilet, \& Mella, 2014; Wrzus, Müller, Wagner, Lindenberger, \& Riediger, 2013). In addition, SAVI postulates that under the latter circumstances, people need more time to recover because of a diminished physiological flexibility and difficulties in dealing with highly distressing experiences. 
Here, we first test how the distinction between reactivity and recovery helps to understand age-related differences in general responding to emotional situations. Reactivity describes the deviation from a baseline, and recovery denotes the return to the baseline. The measurement of general responses to emotional situations may conflate age differences in reactivity and/or recovery if the beginning and the end of the situation is unknown - that is, the end of reactivity and the beginning of recovery. The additional focus on recovery offers an extended approach regarding affective responses to, and health-related outcomes of, emotional experiences (Boehm \& Kubzansky, 2012; Davidson, 1998; Wrosch, Miller, Lupien, \& Pruessner, 2008). It was partly motivated by theoretical accounts associating recovery time with a vulnerability to psychopathology (Davidson, 1998), and by previous research showing that heart rate recovery after physical exercise proved valuable to predict mortality among middle-aged and older adults (Nishime, Cole, Blackstone, Pashkow, \& Lauer, 2000). We propose a new method to assess recovery by measuring the time until the person has returned to his or her baseline level. Thus, we argue that recovery is not merely an automatic "return to baseline" but is a process of its own that can be subject to affect regulation and can predict health outcomes (Davidson, 1998; Larsen \& Christenfeld, 2011; Linden, Earle, Gerin, \& Christenfeld, 1997; Nishime et al., 2000). In this article, we first review the available evidence on age differences in reactivity and recovery regarding both subjective affective experiences and heart rate-two central affect components that have been studied most often and that are central for psychological and physiological health (Charles \& Carstensen, 2010; Cohen et al., 2000; Steptoe, Dockray, \& Wardle, 2009). We focus on laboratory studies in which the emotion-eliciting situation is the same for all participants, and leave out studies on daily life hassles, because daily hassles tend to differ between people. We then address the issue of affective coherence, that is, co-occurring changes in affective experiences and physiological measures, to examine whether coherence changes with age. Finally, we explain the rationale of the present study to show how it extends the currently available evidence.

\section{Prior Research on Age Differences in Experiential and Heart Rate to Unpleasant Emotional Situations}

\section{Reactivity}

Two reviews summarizing studies on age differences in experiential reactivity concluded that reactivity in negative affect is comparable for younger and older adults (Charles, 2010; Levenson, 2000). However, contrary findings exist also: Kunzmann and colleagues found increased affective reactivity with older age to film clips with content presumably more relevant for older people, for example, bereavement or Alzheimer's disease (Kunzmann \& Grühn, 2005; Kunzmann \& Richter, 2009). Charles and Carstensen (2008) found decreased reactivity for older adults when faced with an unpleasant interpersonal situation. Interpersonal situations may represent an exception, as it has been argued that older adults try to avoid or respond less strongly to interpersonal conflicts in daily life (Birditt, Fingerman, \& Almeida, 2005; Blanchard-Fields, Mienaltowski, \& Seay, 2007; Neupert, Almeida, \& Charles, 2007).
For heart rate reactivity in unpleasant situations, a meta-analysis has shown less pronounced reactivity with older age (Uchino et al., 2010; note that blood pressure reactivity was more pronounced with age, which we address in the Discussion section). Apart from an increased ability to regulate one's affect and accompanying heart rate changes, a generally reduced cardiovascular flexibility has been discussed as a potential contributor to this effect (Charles, 2010; Uchino et al., 2010; Uchino, Uno, Holt-Lunstad, \& Flinders, 1999).

Few studies looked at age differences in both subjective experience and heart rate changes in reaction to unpleasant situations. The majority of these also reported no significant age differences in subjective experience, and less pronounced reactivity of heart rate, with older age, to unpleasant experiences (Kudielka, BuskeKirschbaum, Hellhammer, \& Kirschbaum, 2004; Kunzmann, Kupperbusch, \& Levenson, 2005; Labouvie-Vief, Lumley, Jain, \& Heinze, 2003; Levenson, Carstensen, Friesen, \& Ekman, 1991). This pattern matches the conclusions on age effects in experiential (Charles, 2010; Levenson, 2000) and heart rate reactivity (Uchino et al., 2010) reported previously. However, a few studies found different age effects, such as greater physiological and experiential reactivity with older age (Seider, Shiota, Whalen, \& Levenson, 2011), or no significant age differences in changes of both heart rate and subjective experience (Aupée \& Jönson, 2008; Steptoe, Moses, \& Edwards, 1990; Uchino et al., 1999). These divergent age patterns may reflect a specific age relevance of sad situations (Seider et al., 2011), or methodological issues such as small sample sizes.

Thus far, we have focused on mean-level increases as an indicator of reactivity. In addition, the rise-to-peak time-that is, how long it takes until peak negative affect or peak heart rate is reached-could serve as another indicator of reactivity (e.g., Davidson, 1998). Apart from a study with heart transplant patients, who showed slower rise to peak compared with healthy controls (Toledo, Pinhas, Aravot, Almog, \& Akselrod, 2002), we are not aware of a study that included rise-to-peak time in their measures of cardiovascular reactivity.

In sum, although it is assumed that with age, affect regulation increases and, therefore, affective reactivity decreases, the empirical evidence suggests that changes in subjective experience and physiology diverge with age: Reactivity in subjective experiences is often similar across age groups-with a possible exception of sadness and emotional reactions in interpersonal situationswhereas heart rate reactivity is less pronounced with older age. Only a few studies have attended to age differences in experiential and physiological responses after the negative situation had ended, that is, to age differences in the recovery phase of affect dynamics. We review the evidence from these studies next.

\section{Recovery}

Conceptually, affective recovery can be distinguished from reactivity as the return to baseline after the initial reaction (Christenfeld, Glynn, \& Gerin, 2000; Linden et al., 1997). Empirical evidence, however, is still very scarce. Studies focused solely on physiological changes and age differences are unclear because of the methodological limitations of current measurements of recovery. These measurements involved comparisons of heart rate values during an unpleasant emotional situation, with average 
heart rate values during a recovery phase lasting between 1 and $5 \mathrm{~min}$. The studies did not observe significant age differences in heart rate differences between these conditions (Kudielka et al., 2004; Kunzmann et al., 2005; Steptoe et al., 1990; von Schéele, von Schéele, Hansson, Winman, \& Theorell, 2005). Yet comparisons of average heart rate during an emotional situation and a fixed recovery phase may not capture individual differences in recovery well because, depending on the chosen time interval, participants may have either not yet or already recovered. Furthermore, these studies did not report whether subjective experience recovered as well, that is, whether heightened negative affect decreased and regained baseline values.

In short, longer physiological recovery with older age is assumed theoretically (SAVI; Charles, 2010), yet no reliable knowledge on age differences in recovery from unpleasant emotional situations is available thus far: Age differences in subjective experience have been disregarded, and precise measures of physiological recovery time, that is, the duration until heart rate values return to their baseline level, have not yet been obtained.

\section{Prior Research on Age Differences in Affect Coherence}

Earlier studies have often focused on either affective experiences or physiological changes. Yet affective states during distressing, but also during pleasant situations, are phenomena that comprise changes in subjective experience and physiology (Cohen et al., 2000; Plutchik, 1984; Scherer, 1984). These affect components should go hand in hand: For instance, feeling stressed should go along with an increased motivation to change the situation, and with physiological changes (e.g., heart rate and cortisol secretion increases; Almela et al., 2011; Cohen et al., 2000; Dickerson, \& Kemeny, 2004) that provide the necessary energy to implement these motivational tendencies. However, empirical evidence of such coherence between changes in affective experiences and physiology is typically not very strong (Cohen et al., 2000; Mauss $\&$ Robinson, 2009). This may be related to experiences and physiology being differentially susceptible to regulation by the individual, and to measurement error, for example, subjective experiences being less precisely measured than physiological changes for some individuals (Mauss, Levenson, McCarter, Wilhelm, \& Gross, 2005). Nonetheless, coherence among changes in experience and physiology is a prevailing theoretical position. That is, it is assumed that these components of affective states should show synchronized (i.e., coherent) changes to allow for functional responses to environmental demands.

So far, age differences in coherence have been addressed only theoretically. Coherence could decrease with age-but not fully disappear-because biological aging would affect the physiological component, but not necessarily the subjective experience, of affective states (Levenson, 2000). In addition, the theoretically assumed age-related increases in regulatory abilities should be related more strongly to experiential than to physiological components of affective states, as the former are more accessible to conscious regulation than the latter for most individuals. Taken together, biological aging and affect regulation might thus affect experiential and physiological components differently. This could explain the divergence in affective reactivity in the studies reviewed here, which often found no age differences regarding reactivity of affective experiences, but less pronounced heart rate reactivity with older age.

\section{Present Research and Hypotheses}

The present research aimed to establish reactivity and recovery as two distinct components of affect dynamics that might vary with age. In addition, we addressed methodological limitations of prior studies by focusing on both subjective experience and physiology, and by including time-based indicators of reactivity and recovery. We conducted an experiment in which unpleasant affect was elicited in an age-heterogeneous sample using a social-cognitive stress task. As explained in greater detail in the Procedure section, the difficulty of the stress-inducing arithmetic task was adjusted to participants' performance level to ensure a comparable level of stressfulness of the situation. Participants' heart rate was continuously recorded using electrocardiography, and their momentary affective experience was repeatedly assessed.

In line with circumplex models of affective experience (Russell, 1980; Watson \& Tellegen, 1985), we distinguished high-arousing negative affect (e.g., stressed) from low-arousing negative affect (e.g., disappointed). The emotional situation in this experiment was expected to be primarily stressful, that is, to influence mainly high-arousing negative affect. Regarding physiological changes, we focused on heart rate because it reflects sympathetic, that is, activating or reacting, and parasympathetic, that is, calming or recovering, influences necessary for energy supply in both emotionally and physically demanding situations (Burg \& Pickering, 2011). Thus, heart rate seemed to be well suited to analyze reactivity and recovery in an emotional and a physical control situation.

Extending previous research, we distinguished heart rate reactivity from recovery using a newly developed approach to measure heart rate recovery, which is explained in the Method section. In addition, previous studies on affective reactivity could not pinpoint whether age effects in heart rate changes reflect emotion-specific or general properties of the aging cardiovascular system because no comparison with a control task was made. In the present study, we included a control task in which participants exerted physical effort through walking. Relating participants' heart rate changes in both the emotional situation and the control tasks allowed us to explore whether age differences in heart rate changes are specific to the emotional situation.

We propose the following hypotheses: With age, heart rate reactivity to an unpleasant emotional situation should be smaller and slower with age because of potentially increased affect regulatory abilities and decreased heart rate flexibility. Heart rate recovery should be prolonged with age. Again, this could be related to diminished heart rate flexibility, which now cannot be buffered by potential affect-regulatory abilities once the heart rate is elevated. We further explore the coherence between changes in subjective experience and heart rate. We assume that the association between the two weakens with older age because subjective experience and physiology should be differently susceptible to regulatory efforts and biological changes, and because previous studies showed diverging age differences for subjective experiences and cardiovascular measures during unpleasant emotional situations. 


\section{Method}

\section{Participants}

A community sample of 92 participants (45\% men) participated in the current study. The sample was approximately stratified by age (14 to 18 years, $11 \% ; 19$ to 29 years, $19 \%$; 30 to 39 years, $17 \%$; 40 to 49 years, $15 \%$; 50 to 59 years, $13 \%$; 60 to 69 years, $16 \% ; 70$ to 85 years, $8 \%$ ). Participants' age ranged from 14.7 to 83.2 years $(M=42.4, S D=19.0)$. Cardiovascular data from three participants were unavailable because of technical problems $(n=$ 1 ) or because cardiac arrhythmia made the electrocardiograms (ECGs) uninterpretable $(n=2)$.

\section{Procedure}

Participants came to the laboratory, and after they gave consent for participation, trained experimenters attached surface Arbo oneway ECG electrodes in the standard three-lead chest configuration (Huppelsberg \& Walter, 2005): below the lowest left rib at the outer and the middle axillary line, and at the right clavicle. The raw ECG signals were recorded at a sampling rate of $256 \mathrm{~Hz}$. For the control task, participants' physical activity was measured with a three-dimensional acceleration sensor placed at the sternum and a one-dimensional acceleration sensor attached to the right thigh. The acceleration signals were recorded at a sampling rate of $64 \mathrm{~Hz}$, together with ECG signals on biosignal recorders Varioport from Becker Meditec. Participants first completed a physical control task and then took part in the social-cognitive stress task. This fixed order ensured that there were no emotional spillover effects from the emotional to the physical task (Brose, Schmiedek, Lövdén, \& Lindenberger, 2011).

Social-cognitive stress task. During the task, participants continuously lay supine on their back to avoid confounding influences of changes in physical activity and posture (Fahrenberg, Foerster, Smeja, \& Mueller, 1997). After an initial 3-min resting phase, participants rated their momentary affective experiences. Then, a paradigm to induce mild stress that is comparable across individuals (Cacioppo et al., 1995) was implemented. This was immediately followed by a second affect rating and another resting period of 3 min (see Figure 1). After this second rest, participants rated their affective experience a third time. Participants always rated their momentary affective experiences using electronic questionnaires presented on mobile phones (Nokia E50), which participants knew from participation in a prior study (for details, see Riediger et al., 2009). Using mobile phones as assessment devices allowed participants to remain in supine posture throughout the whole task.

The social-cognitive stressor included three trials of a mental arithmetic task in which participants were asked to count backward with specified subtrahends in the presence of an evaluative experimenter. The experimenters were trained to interact demandingly, briefly, and sternly with the participant, and to avoid comforting the participant. Task difficulty was adapted to participants' performance level by varying the subtrahends, with larger subtrahends making the task more difficult (following the procedure proposed by Cacioppo et al., 1995). The adjusted task difficulty and a strictly prescribed script for the evaluative experimenters aimed at a comparable level of stressfulness of the evaluative situation for participants.
Physical control task. The aim was to elicit comparable physical effort across the age-heterogeneous sample in a neutral, nonemotional task. Participants executed six motions and postures for 40 s each: walking at a slow pace, walking upstairs, walking downstairs, walking at a moderate pace, standing, and sitting (Foerster \& Fahrenberg, 2000). The motions were chosen because they were all upright, and deviation from an upright posture is known to influence cardiac activity (Fahrenberg et al., 1997).

At the end of the experiment, participants answered several self-report measures regarding health and personal characteristics. The ethics committee of the Max Planck Institute for Human Development approved the study.

\section{Measurements}

Affective experience. Participants reported their negative affect by rating six affective adjectives on a scale ranging from 0 (not at all) to 6 (very much). Answers regarding "nervous," "tense," and "stressed" were averaged to represent high-arousing negative affect (Cronbach's alpha $=.55, .73$, and .80 for the three measurement occasions-before and after the social-cognitive stressor, and after the recovery phase). The aggregated responses to "disappointed," "sad," and "depressed" yielded an indicator for low-arousing negative affect (Cronbach's alpha $=.70, .65$, and .80). Confirmatory factor analyses showed excellent fit of this assumed two-factor structure for the first (comparative fit index $[\mathrm{CFI}]=.975$; root mean square error of approximation $[$ RMSEA $\left.]=.061 ; \chi^{2}[8]=10.64, p=.22\right)$, the second $(\mathrm{CFI}=$ $.997 ;$ RMSEA $\left.=.023 ; \chi^{2}[8]=8.36, p=.40\right)$, and the third rating $(\mathrm{CFI}=1.00$; RMSEA $=.000 ;[8]=7.70, p=.46)$.

Cardiovascular activity. Heart rate (in beats per minute [bpm]) was calculated based on interbeat intervals. When analyzing heart rate reactivity, the heart rate was aggregated for each period of the experimental phases, for instance, Rest 1 or socialcognitive stress task (see Figure 1, which also shows the duration of each experimental phase). Thus, for the stress task, one mean value for the entire task was calculated. When analyzing heart rate rise-to-peak and recovery times, moving averages of heart rate were computed (see Statistical Analyses section for details).

Physical activity. Physical activity values during the physical tasks were computed as described by Fahrenberg and colleagues (1997). First, values from the two acceleration sensors were detrended by linear regression to remove any linear drift of measurements over time and corrected for the influence of the gravitational force exerted on the acceleration sensors depending on posture. The absolute values of these adjusted measurements were summed for each motion or posture phase and divided by the length of each phase to yield an indicator of participants' average absolute physical activity per minute.

Health and fitness status. Participants' weight and height were measured. They answered questionnaires on their general physical fitness, and the name and type of any medication they used on the day of the data assessment. Based on patient information sheets and with the support of a physician, we classified whether the reported medication affects participants' heart rate ( $1=$ "yes," $0=$ "no," with the latter being the case for $86 \%$ of participants). We used the sum of hours spent on physical activities during a typical week, such as walking, gardening, swimming, biking, dancing, and so forth, as an indicator of participants' 


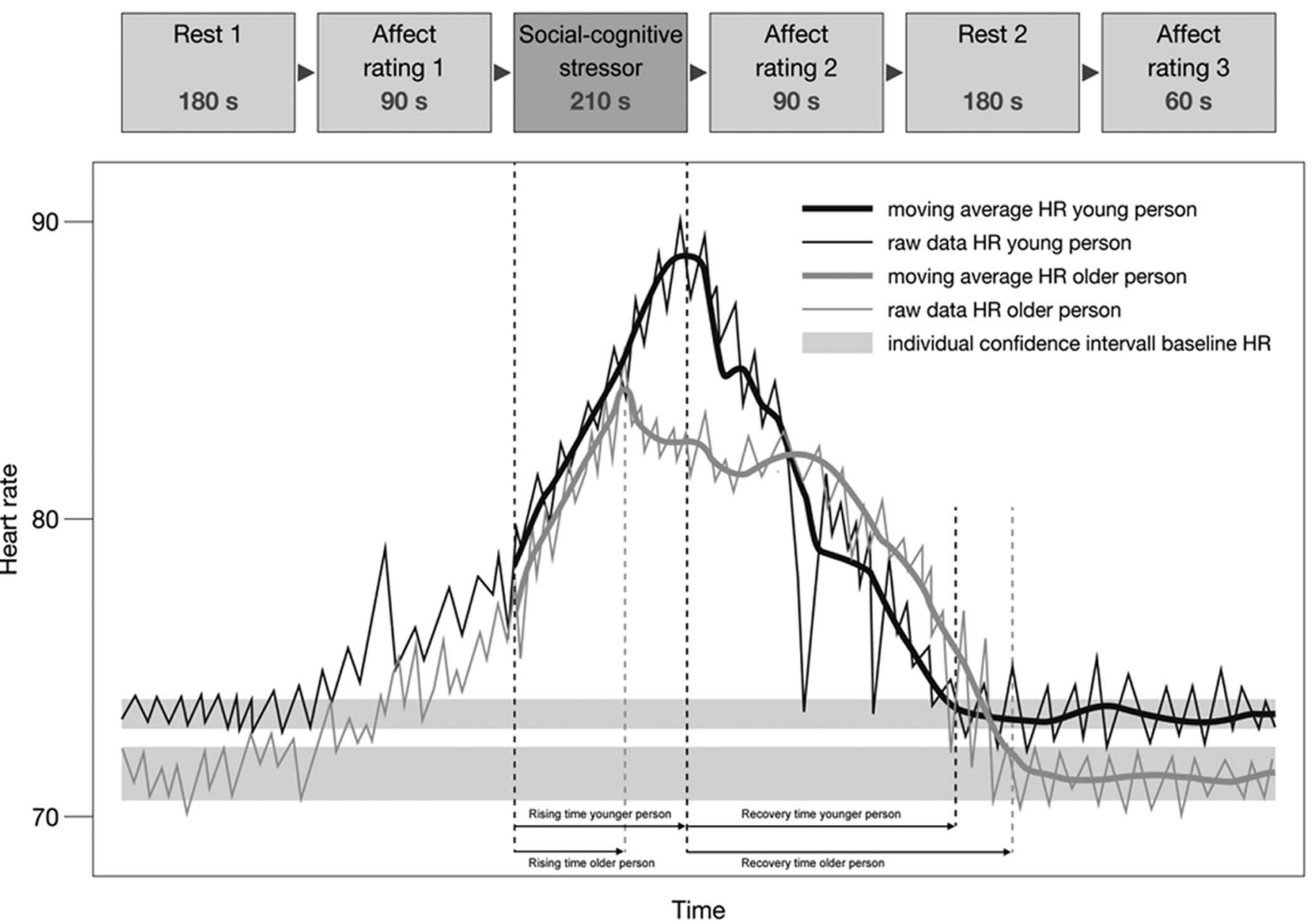

Figure 1. Procedure of social-cognitive stress task. Below are schematic heart rate curves for an assumed younger person and an older person that show how the heart rate changes during the social-cognitive stressor task. Hypothetical rise-to-peak and recovery times for the assumed younger and an older person are shown. The graph for the young person (black lines) demonstrates the advantage of moving averages: Although single readings of raw heart rate are already within the individual confidence interval shortly after the end of the social-cognitive stressor, the moving average (thick black line) reliably reaches the confidence interval later (see dashed line that marks the recovery time).

regular fitness activities $(M=2.47, S D=2.38)$. Participants' body mass index $(M=26.0, S D=5.3)$ was calculated by dividing our laboratory measurements of each participant's weight in kilograms by their squared height in meters.

Task compliance during the social-cognitive stress task. Task compliance was inferred from the achieved task difficulty and the attainment level of the mental arithmetic task. Task difficulty was computed as average subtrahends of the second and third trials, which depended on the performance of the previous trial. The attainment level was approximated by the average percentage of correctly calculated numbers in all three trials.

\section{Operationalization of Reactivity and Recovery}

Reactivity. We operationalized reactivity as changes in mean levels from the baseline to the social-cognitive stressor phase. Regarding affective experiences, the change between Affect Ratings 1 and 2 (baseline and directly after the social-cognitive stressor; Figure 1) indicated reactivity. Regarding heart rate, the change in average heart rate from the baseline (Rest 1) to the social-cognitive stressor phase (see Figure 1) denoted reactivity. During the physical control task, we compared average heart rates during moderate walking with a 40-s period of standing before the motions were executed to measure reactivity.

In addition, we computed heart rate rise-to-peak times as a time-based indicator of reactivity. Within the social-cognitive stressor phase, we first computed moving averages of heart rate to obtain more reliable measures of heart rate compared with single readings (see next paragraph for elaboration on this argument). Next, we determined the highest heart rate during the socialstressor phase and calculated the time from the beginning of the stressor phase to the peak heart rate. We estimated the rise-to-peak time during the physical control task in the same manner: We computed moving averages of heart rate values during the phase of moderate walking, determined the peak heart rate during this 
physical effort phase, and calculated the time from the beginning of moderate walking to the peak heart rate. ${ }^{1}$

Recovery. Recovery regarding affective experiences was operationalized as change between Ratings 2 and 3 (directly after the social-cognitive stressor and after the recovery phase; Figure 1). Heart rate recovery from the stressor was operationalized as time after the end of the stressor until participants had regained their baseline heart rate values. We computed individual $1 \%$ confidence intervals of heart rate baseline values from six 30-s intervals of the first 180-s baseline measurement (Rest 1; Figure 1), and calculated the time until participants were within their individual confidence interval for the first time after the social-cognitive stressor (see Figure 1). To do this, moving averages of 30-s windows of heart rate (lag $5 \mathrm{~s}, 49$ windows on average) were computed from the end of the social-cognitive stressor until the end of the second resting period (see Figure 1) and compared with the individual baseline confidence interval. Thirty-second windows were chosen to obtain reliable measures of mean heart rate, and the chosen lag allowed for a 5-s resolution of recovery time. Recovery during the physical control task was computed in the same way. Here, the confidence interval of the baseline heart rate was computed in the standing phase before the physical tasks began. Recovery time after the end of the moderate walking was computed while participants were again standing. Using baseline confidence intervals and moving averages circumvented the problem raised by Linden and colleagues (1997) of comparing unreliable single readings to determine recovery time. Our approach directly assessed time taken to reach the individual baseline level. In contrast to curve-fitting approaches (Christenfeld et al., 2000), our method did not rely on reaching an unspecific stable level that could be higher than the baseline level, that is, indicating incomplete recovery.

\section{Results}

We first show that participants of different age groups were similarly compliant to the social-cognitive stressor task, and then report how reactivity to the stressor regarding both affective experiences and heart rate varied with age. Next, we describe age differences in recovery regarding affective experience and heart rate. Finally, we present coherence among changes of affective experience and heart rate.

\section{No Significant Age Differences in Compliance to the Social-Cognitive Stressor Task}

First, we analyzed task difficulty and attainment level to see whether the social-cognitive stressor task was comparable for people from different age groups. The average task difficulty was relatively high (subtrahend $M=6.99, S D=2.20$ ), yet it was not significantly related to participants' age, $r=.11, p=.29$. In addition, we approximated the attainment level as average percentage of correct numbers calculated $(M=0.60, S D=0.16)$, which was also not significantly related to participants' age, $r=.09, p=$ .38. These results ruled out the assumption that older participants completed the social-cognitive stressor task less compliantly, that is, that they were less involved in the arithmetic task than younger participants.

\section{Comparable Reactivity of Negative Affect Across Age, Less Pronounced and Slower Heart Rate Reactivity in Unpleasant Emotional Situation With Older Age}

Reactivity of negative affect. We analyzed reactivity, that is, changes in negative affect from baseline to the socialcognitive stressor phase with multilevel modeling (using HLM 6.0; Raudenbush, Bryk, \& Congdon, 2004) because repeated measurements were nested in persons. Multilevel models can be applied to repeated measures designs (Hoffman \& Rovine, 2007), and possess greater flexibility regarding missing values and continuous moderators of change than repeated measures ANOVA. The time of assessment (baseline $=0$; during the stressor $=1$ ) predicted negative affect within persons on Level 1. Age of participants was included as a continuous Level 2 predictor, varying between persons.

During baseline (i.e., prior to the social-cognitive stressor), there were no significant age differences regarding higharousing negative affect $\left(b_{\text {age }}=0.01, S E=0.01, p=.30\right.$ ) or low-arousing negative affect $\left(b_{\text {age }}=-0.01, S E=0.004, p=\right.$ .25). Because of the social-cognitive stressor task, higharousing negative affect significantly increased compared with baseline levels (multilevel change coefficient $b=1.24, S E=$ $0.13, p<.001$, Cohen's $d=-1.09$ ), but there were no significant age effects in this respect (interaction with age: $\left.b_{\text {age }}=-0.01, S E=0.01, p=.35\right)$. Low-arousing negative affect did not significantly increase under the stressor $(b=$ $0.09, S E=0.08, p=.29)$, and there were again no significant age differences (interaction with age: $b_{\text {age }}=-0.01, S E=0.01$, $p=.11$ ). Table 1 provides descriptive statistics for the study.

Reactivity of heart rate. We used a similar multilevel model as before: The time of assessment (baseline $=0$; during the stressor $=1$ ) predicted heart rate on Level 1, and betweenperson variables, for instance, age, health, and fitness, were included as Level 2 predictors. On average, heart rate increased significantly because of the social-cognitive stressor (increase $b=11.80, S E=0.79, p<.01)$. This reactivity was less pronounced with increasing age $(b=-0.11, S E=0.04, p=$ $.01)$. There were no significant quadratic age effects on heart rate reactivity $(b=-0.001, S E=0.003, p=.76)$, and the linear age difference in reactivity was robust after controlling for health and fitness (see Table 2). ${ }^{2}$

Effects were substantial, with a predicted increase of about $12 \mathrm{bpm}$ for a middle-aged adult. Simple slope analyses showed that heart rate increased by about $15 \mathrm{bpm}$ in adolescents, and only by $9 \mathrm{bpm}$ in older participants. This difference corresponds to older participants showing about $60 \%$ of the heart rate reactivity of an average adolescent. Importantly, this amount of

\footnotetext{
${ }^{1}$ Because the phase of moderate walking lasted $40 \mathrm{~s}$, we computed heart rate moving averages of 10 -s windows with a 5-s lag for the socialcognitive stress and the physical control task. The results reported for heart rate rise-to-peak time during the social-cognitive stressor were nearly identical when 30-s windows (lag $5 \mathrm{~s}$ ) were chosen instead for this longer task (duration $M=223 \mathrm{~s}$ ).

${ }^{2}$ The results also remained robust when repeating the analysis after the exclusion of 22 participants who did not change in subjective experience of negative affect in response to the unpleasant emotional situation. These 22 participants did not differ significantly in age from the remaining participants, $t(90)=-1.20, p=.24$
} 
Table 1

Descriptive Statistics of Affective Experience and Heart Rate Before, During, and After the Social-Cognitive Stressor

\begin{tabular}{|c|c|c|c|}
\hline & Before the stressor & During the stressor & After the stressor \\
\hline & $M(S D)$ & $M(S D)$ & $M(S D)$ \\
\hline High-arousing negative affect & $0.66^{\mathrm{a}}(0.79)$ & $1.90^{\mathrm{b}}(1.43)$ & $0.60^{\mathrm{a}}(0.93)$ \\
\hline Low-arousing negative affect & $0.32(0.70)$ & $0.41(0.76)$ & $0.30(0.77)$ \\
\hline Heart rate ${ }^{\mathrm{a}}$ & $73.00^{\mathrm{a}}(11.54)$ & $84.95^{\mathrm{b}}(12.95)$ & $73.71^{\mathrm{a}}(11.04)$ \\
\hline
\end{tabular}

Note. Means with different subscripts differ significantly, with $p<.05$.

${ }^{a}$ Heart rate values refer to the first rest, the social-cognitive stressor task, and the second rest phase (see Figure 1).

heart rate change occurred while participants were physically inactive and lying supine. Figure 2 depicts observed values for baseline heart rate and increase because of the social-cognitive stressor for four about equally sized age groups.

People reached their peak heart rate, on average, at $124.3 \mathrm{~s}$ $(S D=117.5)$ after the beginning of the social-cognitive stressor. ${ }^{3}$ Rise-to-peak time was longer with older age $(r=.19, p=$ $.04)$, which means that older people reached their peak heart rate later than younger people. Figure 3 depicts observed values in rise-to-peak times for four age groups. There were no significant quadratic age effects $(b=-0.02, S E=0.04, p=.74)$, and the linear age effect in rise-to-peak time was robust after controlling for health, fitness, and gender (see Table 3). In addition, men reached their peak heart rate, on average, later than women in this study. ${ }^{4}$

To explore whether age differences in heart rate reactivity are specific to the affective situation, we correlated the values of heart rate reactivity from the social-cognitive stressor and the physical control task (we did this separately for mean-level reactivity and rise-to-peak times). ${ }^{5}$ First, we confirmed with multilevel analyses that there was heart rate reactivity because of physical effort: Heart rate increased significantly from standing to moderate walking (increase $b=22.24, S E=1.17, p<$ $.01)$, and there were no significant age differences $(b=-0.08$, $S E=0.06, p=.23)$. Participants' physical activity, as measured by acceleration sensors, was higher during moderate

Table 2

Heart Rate Reactivity to the Experimental Social-Cognitive Stressor: Unstandardized Coefficients From Multilevel Models

\begin{tabular}{lcc}
\hline & \multicolumn{2}{c}{ Heart rate } \\
\cline { 2 - 3 } & $b$ & $S E$ \\
\hline Intercept & $73.84^{* *}$ & 1.34 \\
Age $^{\mathrm{a}}$ & -0.02 & 0.08 \\
Physical fitness $^{\mathrm{a}}$ & 0.93 & 0.69 \\
Cardiac medication $^{\mathrm{b}}$ & -4.01 & 3.02 \\
Body mass index $^{\mathrm{a}}$ & $0.58^{*}$ & 0.24 \\
Reactivity to stressor (slope) $^{\text {a }}$ & $11.89^{* *}$ & 0.82 \\
Reactivity to stressor $\times$ Age $^{\mathrm{a}}$ & $-0.10^{*}$ & 0.05 \\
Reactivity to stressor $\times$ Physical fitness $^{\mathrm{a}}$ & -0.08 & 0.34 \\
Reactivity to stressor $\times$ Cardiac medication $^{\mathrm{b}}$ & -0.98 & 2.55 \\
Reactivity to stressor $\times$ Body mass index $^{\mathrm{a}}$ & -0.01 & 0.15 \\
\hline a Grand-mean centered. ${ }^{\mathrm{b}} 1=$ yes, $0=$ no. $^{*}$ & & \\
${ }^{*} p<.05 . \quad{ }^{* * *} p<.01$. & &
\end{tabular}

walking compared with standing (increase $b=3.31, S E=0.04$, $p<.001$ ), but this increase in activity did not differ significantly with participants' age, $b=0.003, S E=0.002, p=.24$. Importantly, heart rate reactivity during the physical control task and the social-cognitive stressor task were not significantly correlated: age-controlled partial $r=.15, p=.22$ (zero-order $r=.18, p=.12$ ). Next, we correlated the heart rate rise-to-peak times for the social-cognitive stressor and the physical control task. On average, people reached their peak heart rate during moderate walking after $30.6 \mathrm{~s}(S D=11.4 \mathrm{~s})$, and there were no significant age differences $r=.08, p=.24$ Consistent with the absent association of mean-level reactivity, rise-to-peak times in the physical control task and the socialcognitive stressor task were not significantly correlated: agecontrolled partial $r=.07, p=.28$ (zero-order $r=.08, p=.23$ ). Thus, heart rate reactivity during both tasks was rather distinctive.

\section{Comparable Recovery Regarding Negative Affect Across Age and Slower Heart Rate Recovery from Unpleasant Emotional Situation With Older Age}

Recovery regarding negative affect. After the end of the social-cognitive stressor between the second and the third affect measurement, high-arousing negative affect decreased significantly (coefficient from multilevel regression model: $b=-1.22$,

\footnotetext{
${ }^{3}$ The two measures of heart rate reactivity were negatively associated: faster rise-to-peak time related to stronger increases in heart rate mean levels $(r=-.20, p=.04)$.

${ }^{4}$ There were no significant main effects of gender or interactions with age regarding the reactivity of high-arousing or low-arousing negative affect, heart rate reactivity amplitude, or heart rate recovery time.

${ }^{5}$ In the current study, there was not enough power to observe differences between heart rate reactivity during the social-cognitive stressor and the physical control task in one model using interaction terms. For mean heart rate reactivity, the tested three-way interaction in the multilevel model (Stressor Reactivity $\times$ Age $\times$ Task Type) was not statistical significant, $t=1.15, p=.25$, estimated power .11 . For heart rate rise-to-peak time, the interaction (Age $\times$ Task Type) was significant, $F(1,82)=4.06, p=.047$, observed power .51 . Power estimation suggested that at least 500 participants are necessary to observe significant Task $\times$ Age interactions with $\alpha=.05$ and a power of .80 . We therefore decided to correlate individual heart rate reactivity values from the social-cognitive stressor and the physical control task to analyze, whether people's heart rate reactivity during the emotional situation is similar to their heart rate reactivity during the physical task. Strong correlations would have suggested similar heart rate reactivity independent of the nature of the situation.
} 


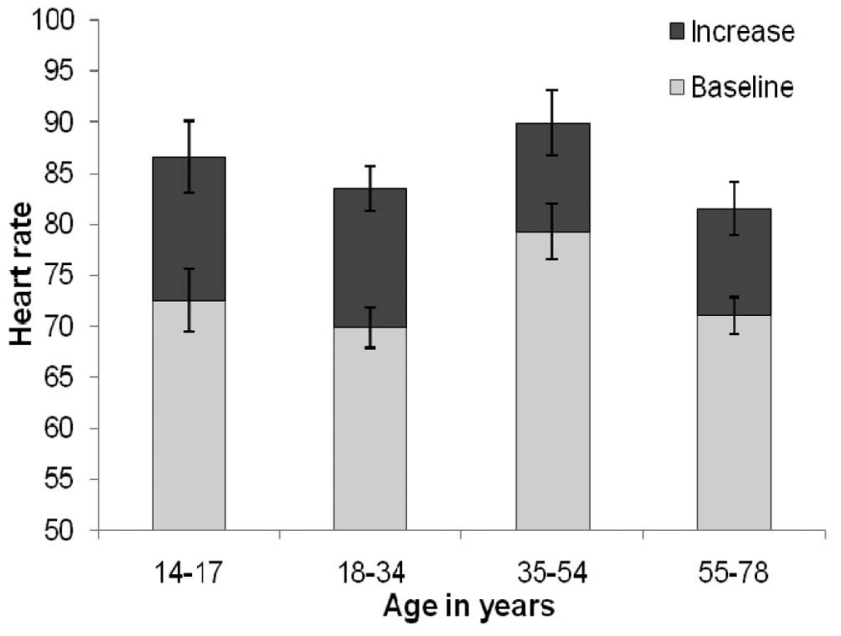

Figure 2. Observed age differences in heart rate reactivity to the socialcognitive stress task. Age groups are chosen to be about equally sized. Error bars represent \pm 1 standard errors of the mean.

$S E=0.14, p<.001$, Cohen's $d=0.95)$ and returned to the baseline level (see Table 1). There were no significant age differences in either high-arousing negative affect during the socialcognitive stressor $(b=0.004, S E=0.01, p=.96)$ or the decrease of high-arousing negative affect from the second to the third affect measurement $\left(b_{\text {age }}=-0.001, S E=0.01, p=.91\right)$. Again, low-arousing negative affect did not decrease significantly $(b=$ $0.09, S E=0.08, p=.29)$, and there were no significant age differences in the decrease $\left(b_{\text {age }}=-0.01, S E=0.01, p=.11\right)$. With age, people reported slightly less low-arousing negative affect during the social-cognitive stressor $\left(b_{\text {age }}=-0.01, S E=\right.$ $0.004, p=.01)$.

We tested whether reactivity was related to recovery regarding subjective experiences: We computed the correlations between the increase in negative affect from the baseline to the socialcognitive stressor (i.e., reactivity) and the level of negative affect after recovery. ${ }^{6}$ The increase in negative affect because of the stressor, that is, reactivity, was not significantly related to the level of negative affect after the recovery phase: for high-arousing

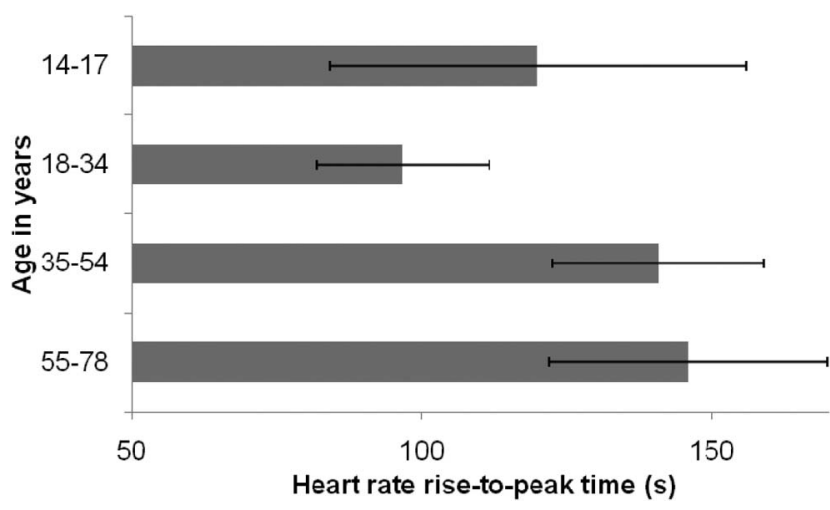

Figure 3. Observed age differences in heart rate rise-to-peak time during the social-cognitive stress task. Age groups are chosen to be about equally sized. Error bars represent \pm 1 standard errors of the mean.
Table 3

Heart Rate Rise-To-Peak Time During the Experimental SocialCognitive Stressor: Unstandardized Coefficients From Multiple Regression Models

\begin{tabular}{lcr}
\hline & \multicolumn{2}{c}{ Heart rate rise-to-peak time } \\
\cline { 2 - 3 } & $b$ & $S E$ \\
\hline Constant & 130.47 & 13.42 \\
Age & $1.42^{*}$ & 0.70 \\
Gender & $41.70^{* * *}$ & 12.35 \\
Physical fitness $_{\text {Cardiac medication }}{ }^{\mathrm{b}}$ & -3.97 & 5.31 \\
Body mass index & 11.39 & 39.99 \\
${ }^{\mathrm{a}} 1=$ male, $-1=$ female. & ${ }^{\mathrm{b}} 1=$ yes, $0=$ no. \\
${ }^{*} p<.05 .{ }^{* *} p<.01$. & & \\
& &
\end{tabular}

negative affect, $r=.02, p=.43$; for low-arousing negative affect, $r=-.14, p=.11$.

Recovery regarding heart rate. On average, people took $87.6 \mathrm{~s}(S D=110.6)$ until their heart rate was within their individual $1 \%$ confidence interval of baseline heart rate. With age people needed more time to regain baseline heart rate, $r_{\text {age }}=.20, p=.03$. There were no significant quadratic age effects $(b=-0.01, S E=0.04, p=.77)$, and the linear age effect remained significant when controlling for heart rate reactivity, health, and fitness indicators in a multiple regression model, $F(7,76)=4.08, p=.001, R^{2}=29 \%($ see Table 4$)$. Again, the size of the age effect was substantial: With every age decade, participants took about $18 \mathrm{~s}$ longer to regain their baseline heart rate. Figure 4 depicts observed values of heart rate recovery time for four age groups. Table 4 also shows that people with stronger reactivity, that is, heart rate increase because of the social-cognitive stressor, took longer until they were within their individual $1 \%$ confidence interval of baseline heart rate. This association was moderated by the age of participants: With age, the positive association between more pronounced reactivity and longer recovery time was stronger.

We additionally examined recovery of heart rate by comparing the average heart rate during the stressor with that during the second rest period (see Table 1), as previous studies have done. The multilevel model was similar to the model analyzing heart rate reactivity. On average, heart rate decreased by estimated $b=-8.52 \operatorname{bpm}(S E=0.58, p<.001)$ between the social-cognitive stressor and the second resting period. Importantly there were no significant age differences in heart rate decrease, $b_{\text {age }}=0.04, S E=0.03, p=.22$. Thus, in contrast to age differences in computed recovery time, there were no significant age differences when comparing average heart rate values during the social-cognitive stressor and during the subsequent, second rest phase.

To explore whether age differences in heart rate recovery are specific to the affective situation, we correlated the recovery times

\footnotetext{
${ }^{6}$ We did not compute correlations between the negative affect change from the baseline to the social-cognitive stressor, or the negative affect change from the social-cognitive stressor to after the recovery. These difference values would be confounded because they both contained the measurement directly after the social-cognitive stressor.
} 
from the social-cognitive stressor and from the physical control task. ${ }^{7}$ During the physical control task, participants took, on average, $22.0 \mathrm{~s}(S D=19.4)$ until their heart rate reached the baseline rate during standing. There was no significant association with participants' age, $b_{\text {age }}=0.18, S E=0.13, p=.18$. Importantly, the heart rate recovery times from the control task and the socialcognitive stressor task were again not significantly correlated: age-controlled partial $r=.12, p=.42$ (zero-order $r=.19, p=$ .08 ). Thus, heart rate recovery times during both tasks were again rather distinctive.

\section{Coherence Between Negative Affect and Heart Rate Changes Is Similar Across Age Groups}

Coherence during reactivity. We computed multilevel models to test whether increases in experienced negative affect cooccurred with increases in heart rate, and whether the coupling between the two varied with age. The change in average heart rate from the baseline to the stressor phase was predicted by the uncentered high- and low-arousing negative affect measured also during the baseline and the social-cognitive stressor phase (Level 1). The age of participants was entered again at Level 2 to predict differences in baseline heart rate (intercept), and in the withinperson association between changes in heart rate and high- or low-arousing negative affect (slopes).

Increases in high-arousing negative affect from before to after the social-cognitive stressor were significantly associated with increases in heart rate $(b=3.90, S E=0.62, p<.001)$, but this association was not significantly moderated by participants' age ( $\left.b_{\text {age }}=-0.05, S E=0.04, p=.22\right)$. That is, increases in higharousing negative affect ratings by 1 scale point were accompanied by increases in heart rate of almost $4 \mathrm{bpm}$, whereas increases of 2 scale points were accompanied by almost $8 \mathrm{bpm}$ heart rate increases. Changes in low-arousing negative affect did not predict changes in heart rate $(b=0.06, S E=1.22, p=.96$; no significant age moderation $\left.b_{\text {age }}=-0.12, S E=0.07, p=.09\right)$. The effects remained the same when computing separate models for high- and low-arousing negative affect, and when additionally controlling for health and physical fitness.

Coherence during recovery. To analyze coherence during recovery, individual heart rate recovery times were predicted by

Table 4

Heart Rate Recovery Time From the Experimental SocialCognitive Stressor: Unstandardized Coefficients From Multiple Regression Models

\begin{tabular}{|c|c|c|}
\hline & \multicolumn{2}{|c|}{$\begin{array}{l}\text { Heart rate recovery } \\
\text { time }\end{array}$} \\
\hline & $b$ & $S E$ \\
\hline Constant & 90.34 & 11.09 \\
\hline Age & $1.36^{*}$ & 0.66 \\
\hline Heart rate reactivity to stressor & $5.03^{* * *}$ & 1.41 \\
\hline Age $\times$ Heart rate reactivity to stressor & $0.20^{* * *}$ & 0.07 \\
\hline Physical fitness & -6.15 & 4.35 \\
\hline Cardiac medication $^{\mathrm{a}}$ & 49.58 & 32.34 \\
\hline Body mass index & 2.48 & 2.07 \\
\hline
\end{tabular}

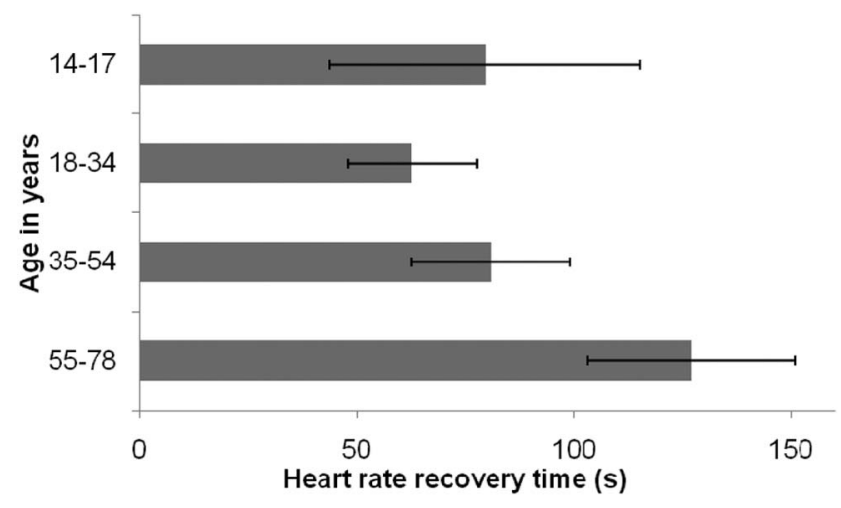

Figure 4. Observed age differences in heart rate recovery time from the social-cognitive stress task. Age groups are chosen to be about equally sized. Error bars represent \pm 1 standard errors of the mean.

the individual change in negative affect from the social-cognitive stressor to the recovery period (second rest), age, and the interaction between age and the change in negative affect in a multiple regression model. Stronger decreases in high-arousing negative affect were related to faster heart rate recovery, that is, shorter recovery time $(b=-15.83, S E=8.11, p=.03, r=-.21)$. This indicates that participants who decreased by 2 scale points in high-arousing negative affect between the social-cognitive stressor and the second rest period were within their individual baseline heart rate almost $16 \mathrm{~s}$ earlier than participants who decreased by 1 scale point. Entering the age of participants and the interaction between age and decreases in high-arousing negative affect did not significantly improve the regression model, $F(2,85)=1.66, p=$ .20 , and neither were significant predictors $\left(b_{\text {age }}=1.03, S E=\right.$ $\left.0.57, p=.08 ; b_{\text {interaction }}=0.12, S E=0.43, p=.79\right)$. All effects remained the same when additionally controlling for average negative affect during the social-cognitive stressor, health, or physical fitness.

\section{Summary of Results}

In sum, the changes in experienced negative affect because of the social-cognitive stressor-both reactivity and recovery-were comparable across age groups, whereas heart rate reactivity to the social-cognitive stressor was less pronounced and slower, and heart rate recovery took longer, with older age. Individual differences in heart rate reactivity and recovery, respectively, were not significantly correlated across the social-cognitive stressor task and a physical control task. The magnitude of negative affect reactivity was not significantly related to the level of negative affect after the recovery phase. In contrast, stronger heart rate

\footnotetext{
${ }^{7}$ As reported for reactivity (see Footnote 5), there was not enough power in the current study to observe differences between heart rate recovery times during the social-cognitive stressor and the physical control task using interaction terms. The Age $\times$ Task type interaction predicting recovery times was not statistical significant, $F(1,83)=1.50, p=.22$, observed power .23 . We decided to correlate heart rate recovery times in both situations to analyze whether people's recovery times during the emotional situation is similar to their recovery time during the physical task. Strong correlations would have suggested similar heart rate recovery independent of the nature of the situation.
} 
reactivity was related to slower recovery from the social-cognitive stressor, and more so with older age. Both reactivity and recovery showed significant coherence: Heart rate reactivity was greater with stronger increases in high-arousing negative affect, and heart rate recovered faster with stronger decreases in high-arousing negative affect. These associations were not significantly moderated by participants' age. Finally, all effects were robust to control for health indicators, and there were no significant age differences in task compliance that could explain age differences in reactivity or recovery.

\section{Discussion}

This research supports the idea that a comprehensive understanding of age differences in affective responses to emotional situations requires the distinction of two components of affect dynamics: reactivity, the deviation from a person's baseline, and recovery, the return to a person's baseline. We demonstrated the utility of this approach focusing on age differences in changes in negative affective experiences and heart rate responses to an unpleasant emotional situation, which was elicited using a socialcognitive stress task. Adjusting the task difficulty to participants' performance levels and standardizing the evaluative behavior of the experimenters ensured a comparable level of stressfulness of the situation across age groups.

The current findings extend previous studies on age differences in affective reactivity in three important points. First, the new approach to assess heart rate recovery revealed age differences that were distinct from age differences in affective reactivity: Heart rate reactivity was less pronounced with age- both with respect to magnitude and speed-and recovery occurred more slowly. This pattern questions assumptions of a generally improved way of handling emotional situations in older age. This pattern, however, supports recent assumptions that physiological recovery would take longer with older age once the reaction has occurred (Charles, 2010; Charles \& Luong, 2013). This may be explained by older adults' presumably greater difficulties in dealing with highly arousing situations related to diminished flexibility of the physiological system (Charles, 2010; Charles \& Luong, 2013; Uchino et al., 1999). Our finding that higher heart rate reactivity was related to even longer recovery time among older adults supports this interpretation. It also underscores the second point: Less intense and slower heart rate reactivity with older age might be functional, as it prevents even longer recovery periods. Older adults are assumed to use affect regulation strategies that avoid unpleasant situations in the first place (Blanchard-Fields et al., 2007; Charles, Piazza, Luong, \& Almeida, 2009). This might be facilitative for their well-being, as it prevents strong reactions that are difficult to deal with. In addition, first evidence from student samples suggests that affect regulation can be differentially effective depending on the timing within the affective process (Sheppes \& Gross, 2011). If older participants do indeed use more affect regulation strategies that take effect at earlier stages of the affective process (Urry \& Gross, 2010), these might be less effective at later stages of the affective process. Third, the combined study of changes in heart rate and in negative affective experiences casts new light on the assumed age differences in their coherence. Here, we found substantial associations between changes in affective experiences and heart rate. These associations seemed to be similar across adoles- cence and adulthood. Next, we first discuss these findings in greater detail, and then explain their implications for theories on affective development.

\section{Age Differences in Affective Reactivity and Recovery}

A prominent theme in the current life span literature is the assumption that people get better at handling their affective reactions in unpleasant situations. Empirical evidence supporting this claim, however, is mixed. It shows that age differences in reactivity depend both on the affect component-subjective experience, physiology, expression - and the kind of affect that is experienced, for instance, stress or sadness (for reviews, see Charles, 2010; Levenson, 2000).

As hypothesized, and in line with previous work (Charles, 2010; Charles \& Luong, 2013; Uchino et al., 1999), we found no significant age differences in increases of negative affect because of the unpleasant emotional situation. We explicitly used a paradigm that challenged participants equally by using a task that was adjusted in difficulty to participants' abilities, in order to make it similarly demanding for different age groups. This is supported by the fact that we found no significant age differences in indicators of task compliance. Under these conditions, people's negative affective experiences were similar across the various investigated age groups.

The expected finding of an age-related decrease in heart rate reactivity is highly consistent with prior evidence (Uchino et al., 2010). As explained before, and in contrast to many previous studies, we created an unpleasant emotional situation that elicited comparable levels of stressfulness across age groups. In this setting, heart rate increases were substantial — on average, $12 \mathrm{bpm}$ in a supine position - and noticeably more pronounced for adolescents and less pronounced for older people. In addition, with older age, heart rate rose more slowly to its peak value during the social-cognitive stress task, but there were no significant age differences in heart rate rise-to-peak time under moderate physical effort. This is the first study to report age differences in heart rate rise-to-peak times, and therefore further studies are needed for deciding whether these are stable findings.

One may object that the age differences in heart rate reactivity to the unpleasant emotional situation observed in this study are not specific to affective responses, but primarily reflect general properties of the aging cardiovascular system. However, we found that individual differences in the amount or the speed of heart rate reactivity to the emotional and a physical control task were not significantly correlated. Thus, people whose heart rate reacted strongly or quickly in the unpleasant emotional situation did not necessarily show the same pattern under physical effort. This speaks against effects of generalized age-related cardiovascular changes and argues for emotion-specific age differences.

We found substantial coherence between changes in experience and physiology, that is, heart rate: Stronger increases in higharousing negative affect were related to more pronounced heart rate reactivity. Both showed diverging age differences, as explained earlier in the article, but we found no substantial age differences in coherence. The nonsignificant age difference does not preclude that coherence of affective experiences and heart rate differs across the life span, as theoretically assumed. The divergence of age effects in affective components could be associated 
with regulatory processes, as a divergence between subjective experiences and physiology has been interpreted as being related to affect regulation (Gross \& Thompson, 2007; Kreibig, 2010). Age-related changes in affect regulation and in the cardiovascular system could thus affect the experiential and the physiological affect component differently (Gross \& Thompson, 2007; Shiota \& Levenson, 2012), which could diminish coherence.

Age differences in recovery from an unpleasant emotional situation have seldom been addressed, both theoretically and empirically. We observed no significant age differences in changes of negative affect during the recovery period, comparable with negative affect reactivity. Negative affect was similarly low across age groups after the recovery phase. This could be attributable to regulatory efforts affecting the experiential but not the physiological component to the same degree, because we observed age differences in heart rate recovery, as explained next. A methodological explanation could be that recovery regarding negative affect also follows a time course that differs between people. Yet when the assessment was made after the recovery period, all participants were back at their baseline level. The recovery time in negative affect could be assessed with continuous experience ratings (e.g., Mauss et al., 2005), which were not available in the current study. In addition, the continuous assessment of affective experiences is more difficult than continuous physiological measurement because participants would have to pay constant attention to their experiences and their reports. In addition to possibly induced reactance to the repeated measure, the cognitive load during the combined monitoring and report might be too demanding for some people, especially in older age.

As expected, we observed that heart rate recovery occurs more slowly with age. Thus, once more, there were diverging age differences in subjective and physiological recovery. Slower heart rate recovery may be attributed to a presumably decreased physiological flexibility with older age (Charles, 2010; Charles \& Luong, 2013; Uchino et al., 1999). Still, we argue that other processes also play an important role. We base this reasoning on the finding that individual differences in heart rate recovery were not significantly correlated across the emotional and the physical tasks, whereas a decreased physiological flexibility with age would have predicted a strong association. The correlation between shorter heart rate recovery duration and stronger decrease in negative affect additionally supports a relation to affective processes. Thus, we also found coherence among subjective and physiological recovery. As for reactivity, this association was also not significantly different for people from different age groups. We again interpret this divergence in age patterns as being related to susceptibility differences of experience and physiology to affect regulation (Gross \& Thompson, 2007; Shiota \& Levenson, 2012).

The distinct age differences in heart rate reactivity and heart rate recovery support the assumption that recovery is not merely an automatic return to baseline (Larsen \& Christenfeld, 2011; Linden et al., 1997); otherwise, less pronounced reactivity with age would have been observed together with faster recovery. Thus far, age differences in recovery have been studied by comparing task with posttask periods without considering the temporal dynamics, and no age differences have been observed (Kudielka et al., 2004; Kunzmann et al., 2005). We argue that this may have been the case because these studies employed unsuitable measures of heart rate recovery. If the measurement interval is too long, most participants will have returned to their baseline values, and potential individual differences cannot be observed. We, too, did not find age differences when comparing average heart rate values under stress with average values during the subsequent 3 -min rest period. This is plausible because the average recovery time was below $90 \mathrm{~s}$. Thus, nearly all participants had recovered during the second rest. The new approach to assess recovery as time until participants' heart rates reach their individual confidence intervals of baseline heart rate thus seems highly promising for studying individual differences in recovery beyond comparisons of mean levels.

\section{Implications for Theories on Affective Development}

Our findings suggest that age differences in affect dynamic processes are multidirectional: Reactivity and recovery regarding negative affect were comparable across age groups, heart rate reactivity was less pronounced, whereas heart rate recovery was slower with age. This means that the conclusion that "the construct of emotion cannot be captured with any one measure considered alone ... . [T] he more measures of emotion that are obtained . . . the more one will likely learn from a particular study" (Mauss \& Robinson, 2009, p. 228) is even more valid when examining affective development. Motivation, life experience, regulatory efforts, and biological changes may exert different influences on affective experiences and related physiological processes. And as the former change differently across the life span (e.g., Baltes, 1987; Charles, 2010; Charles \& Luong, 2013), measuring only one affect component-often subjective experience-limits conclusions on the interplay of such concepts as motivation, regulation, and biological changes.

Of course the observed age patterns in reactivity and recovery regarding negative affect and heart rate are only one example and perhaps not generalizable. The specific age differences depend on characteristics of the situation (Charles, 2010; Charles \& Luong, 2013; Labouvie-Vief et al., 2014; Wrzus et al., 2013). One could speculate that similar age differences to the ones observed here could occur for other high-arousing negative affective states: For instance, similar experiences and less pronounced heart rate reactivity have been found for social situations that induce anxiety (Kudielka et al., 2004) and for autobiographical memories of anger (Labouvie-Vief et al., 2003). In contrast, avoidance of interpersonal conflicts led to less reactivity in negative affect among older people (Charles et al., 2009). However, facing complex hassle situations (Wrzus et al., 2013) or experiencing intense sadness (Kunzmann \& Grühn, 2005; Seider et al., 2011) led to stronger experiential and physiological reactivity among older people. Sadness is assumed to be highly relevant in older adulthood because of its association with loss and goal disengagement (Smith \& Lazarus, 1993; Streubel \& Kunzmann, 2011). Thus, depending on the situation, strengths and vulnerabilities acquired over the life span will take different effects, and will shape the specific pattern of subjective experiences and physiological changes to unpleasant situations.

In sum, our findings show that like age-related differences in the cognitive domain (e.g., Baltes, 1987), those in the affective domain are not unidirectional. Distinguishing between reactivity to, and recovery from, emotional situations revealed distinct patterns of age differences. Less pronounced physiological reactivity could 
indeed possess a compensatory function to prevent even longer recovery phases.

\section{Limitations and Conclusions}

We found that individual differences in heart rate reactivity and recovery, respectively, were not significantly correlated across emotional and physical control tasks. We are aware that the two tasks differed in posture, occurred in a fixed order, and further evidence is needed that the indices of heart rate reactivity and recovery are reliable indicators of individual differences (see Cacioppo, Uchino, \& Berntson, 1994, for such evidence). These limitations render our conclusions tentative. Yet our findings- the age effects in heart rate reactivity and recovery, and the coherence effects during the emotional task-indirectly evince the reliability of the reactivity and the recovery indices. These predicted findings would not have shown with unreliable indices. The findings on coherence additionally support our impression that the age differences in heart rate changes in the unpleasant emotional situation partially represent affective processes and not only general cardiovascular reactions. Thus, these observed age differences in reactivity and recovery during the emotional task may, at least in part, reflect mechanisms that are specific to affective responding.

For physiological measures, we focused on heart rate because it incorporates influences of the activating, sympathetic, and the calming, parasympathetic system; it is sensitive to both emotional and physical demands; and it has been used most often in earlier studies and therefore allows a direct comparison and integration of our results into previous work. Still, it would be desirable to disentangle reactivity and recovery in other physiological measures as well. Generalizations of our findings to other peripheral physiological measures, such as blood pressure or electrodermal activity, may be too quick, as biological aging affects different systems differently (Ferrari et al., 2003; Whitbourne, 2001). Blood pressure reactivity has been shown to be enhanced with age (Uchino et al., 2010), which is highly plausible because blood pressure is controlled by changes in blood vessels and baroreceptors - both strongly affected by nutrition, medication, and lifestyle, and whose effects cumulate over the life course (Ferrari et al., 2003).

We assessed reactivity to and recovery from only one unpleasant, stressful situation. As discussed, addressing reactivity and recovery in other situations - for instance, sad, terrifying, or joyful situations-would broaden the knowledge about age differences in affective dynamics, generally. In addition, assessing more than one situation would allow more precise within-person analyses on the coherence of experiential and physiological changes. Though we found substantial coherence, such analyses would provide even stronger evidence (e.g., Mauss et al., 2005), and could yield additional information on age differences in coherence.

Despite these limitations, the present research adds substantially to our understanding of age differences in affective dynamics by establishing reactivity and recovery as separate affective processes that might be differently susceptible to age-differential regulatory efforts. This has important implications: Methodologically, studies on affective responding should employ study designs that allow the distinction between reactivity and recovery using precise measures of recovery time. Then, recovery time from an unpleasant emotional situation could prove to be a valuable predictor of psychological and physiological health in addition to reactivity (Davidson, 1998; Uchino, Holt-Lunstad, Bloor, \& Campo, 2005). The current study also underscores the multidirectional nature of age differences in affective processes and speaks against the notion of a generally improved affect regulation competence with age: Older people may indeed be less easily annoyed, but take a longer time to cool down.

\section{References}

Almela, M., Hidalgo, V., Villada, C., van der Meij, L., Espín, L., GómezAmor, J., \& Salvador, A. (2011). Salivary alpha-amylase response to acute psychosocial stress: The impact of age. Biological Psychology, 87, 421-429. doi:10.1016/j.biopsycho.2011.05.008

Aupée, A.-M., \& Jönson, P. (2008). Age-related changes of phasic heart rate responses to affective pictures. Scandinavian Journal of Psychology, 49, 325-331. doi:10.1111/j.1467-9450.2008.00659.x

Baltes, P. B. (1987). Theoretical propositions of life-span developmental psychology: On the dynamics between growth and decline. Developmental Psychology, 23, 611-626. doi:10.1037/0012-1649.23.5.611

Birditt, K. S., Fingerman, K. L., \& Almeida, D. M. (2005). Age differences in exposure and reactions to interpersonal tensions: A daily diary study. Psychology and Aging, 20, 330-340. doi:10.1037/0882-7974.20.2.330

Blanchard-Fields, F., Mienaltowski, A., \& Seay, R. B. (2007). Age differences in everyday problem-solving effectiveness: Older adults select more effective strategies for interpersonal problems. The Journals of Gerontology: Series B: Psychological Sciences and Social Sciences, 62, P61-P64. doi:10.1093/geronb/62.1.P61

Boehm, J. K., \& Kubzansky, L. D. (2012). The heart's content: The association between positive psychological well-being and cardiovascular health. Psychological Bulletin, 138, 655-691. doi:10.1037/a0027448

Brose, A., Schmiedek, F., Lövdén, M., \& Lindenberger, U. (2011). Normal aging dampens the link between intrusive thoughts and negative affect in reaction to daily stressors. Psychology and Aging, 26, 488-502. doi: 10.1037/a0022287

Burg, M. M., \& Pickering, T. G. (2011). The cardiovascular system. In R. J. Contrada (Ed.), The handbook of stress science: Biology, psychology, and health (pp. 37-45). New York, NY: Springer.

Cacioppo, J. T., Malarkey, W. B., Kiecolt-Glaser, J. K., Uchino, B. N., Sgoutas-Emch, S. A., Sheridan, J. F., . . G Glaser, R. (1995). Heterogeneity in neuroendocrine and immune responses to brief psychological stressors as a function of autonomic cardiac activation. Psychosomatic Medicine, 57, 154-164. doi:10.1097/00006842-199503000-00008

Cacioppo, J. T., Uchino, B. N., \& Berntson, G. G. (1994). Individual differences in the autonomic origins of heart rate reactivity: The psychometrics of respiratory sinus arrhythmia and preejection period. Psychophysiology, 31, 412-419. doi:10.1111/j.1469-8986.1994.tb02449.x

Carstensen, L. L., \& Charles, S. T. (1998). Emotion in the second half of life. Current Directions in Psychological Science, 7, 144-149. doi: 10.1111/1467-8721.ep10836825

Charles, S. T. (2010). Strength and vulnerability integration: A model of emotional well-being across adulthood. Psychological Bulletin, 136, 1068-1091. doi:10.1037/a0021232

Charles, S. T., \& Carstensen, L. L. (2008). Unpleasant situations elicit different emotional responses in younger and older adults. Psychology and Aging, 23, 495-504. doi:10.1037/a0013284

Charles, S. T., \& Carstensen, L. L. (2010). Social and emotional aging. Annual Review of Psychology, 61, 383-409. doi:10.1146/annurev.psych .093008 .100448

Charles, S. T., \& Luong, G. (2013). Emotional experience across adulthood: The theoretical model of Strength and Vulnerability Integration. Current Directions in Psychological Science, 22, 443-448. doi:10.1177/ 0963721413497013 
Charles, S. T., Piazza, J., Luong, G., \& Almeida, D. M. (2009). Now you see it, now you don't: Age differences in affective reactivity to social tensions. Psychology and Aging, 24, 645-653. doi:10.1037/a0016673

Christenfeld, N., Glynn, L. M., \& Gerin, W. (2000). On the reliable assessment of cardiovascular recovery: An application of curve-fitting techniques. Psychophysiology, 37, 543-550. doi:10.1111/1469-8986 .3740543

Cohen, S., Hamrick, N., Rodriguez, M. S., Feldman, P. J., Rabin, B. S., \& Manuck, S. B. (2000). The stability of and intercorrelations among cardiovascular, immune, endocrine, and psychological reactivity. Annals of Behavioral Medicine, 22, 171-179. doi:10.1007/BF02895111

Davidson, R. J. (1998). Affective style and affective disorders: Perspectives from affective neuroscience. Cognition and Emotion, 12, 307-330. doi:10.1080/026999398379628

Dickerson, S. S., \& Kemeny, M. E. (2004). Acute stressors and cortisol responses: A theoretical integration and synthesis of laboratory research. Psychological Bulletin, 130, 355-391. doi:10.1037/0033-2909.130.3 .355

Fahrenberg, J., Foerster, F., Smeja, M., \& Mueller, W. (1997). Assessment of posture and motion by multichannel piezoresistive accelerometer recordings. Psychophysiology, 34, 607-612. doi:10.1111/j.1469-8986 1997.tb01747.x

Ferrari, A. U., Radaelli, A., \& Centola, M. (2003). Aging and the cardiovascular system. Journal of Applied Physiology, 95, 2591-2597.

Foerster, F., \& Fahrenberg, J. (2000). Motion pattern and posture: Correctly assessed by calibrated accelerometers. Behavior Research Methods, Instruments, \& Computers: A Journal of the Psychonomic Society, Inc, 32, 450-457. doi:10.3758/BF03200815

Gross, J. J., \& Thompson, R. A. (2007). Emotion regulation: Conceptual foundations. In J. J. Gross (Ed.), Handbook of emotion regulation (pp. 3-24). New York, NY: Guilford Press.

Hoffman, L., \& Rovine, M. J. (2007). Multilevel models for the experimental psychologist: Foundations and illustrative examples. Behavior Research Methods, 39, 101-117. doi:10.3758/BF03192848

Huppelsberg, J., \& Walter, K. (2005). Kurzlehrbuch Physiologie [Textbook physiology]. Stuttgart, Germany: Thieme.

Kreibig, S. D. (2010). Autonomic nervous system activity in emotion: A review. Biological Psychology, 84, 394-421. doi:10.1016/j.biopsycho .2010 .03 .010

Kudielka, B. M., Buske-Kirschbaum, A., Hellhammer, D. H., \& Kirschbaum, C. (2004). Differential heart rate reactivity and recovery after psychosocial stress (TSST) in healthy children, younger adults, and elderly adults: The impact of age and gender. International Journal of Behavioral Medicine, 11, 116-121. doi:10.1207/s15327558ijbm1102_8

Kunzmann, U., \& Grühn, D. (2005). Age differences in emotional reactivity: The sample case of sadness. Psychology and Aging, 20, 47-59. doi:10.1037/0882-7974.20.1.47

Kunzmann, U., Kupperbusch, C. S., \& Levenson, R. W. (2005). Behavioral inhibition and amplification during emotional arousal: A comparison of two age groups. Psychology and Aging, 20, 144-158. doi:10.1037/08827974.20.1.144

Kunzmann, U., \& Richter, D. (2009). Emotional reactivity across the adult life span: The cognitive pragmatics make a difference. Psychology and Aging, 24, 879-889. doi:10.1037/a0017347

Labouvie-Vief, G., Gilet, A.-L., \& Mella, N. (2014). The dynamics of cognitive-emotional integration: Complexity and hedonics in emotional development. In P. Verhaegen \& C. Hertzog (Eds.), The Oxford handbook of emotion, social cognition, and everyday problem solving during adulthood (pp. 83-98). New York, NY: Oxford University Press.

Labouvie-Vief, G., Lumley, M. A., Jain, E., \& Heinze, H. (2003). Age and gender differences in cardiac reactivity and subjective emotion responses to emotional autobiographical memories. Emotion, 3, 115-126. doi:10.1037/1528-3542.3.2.115
Larsen, B. A., \& Christenfeld, N. J. S. (2011). Cognitive distancing, cognitive restructuring, and cardiovascular recovery from stress. Biolog ical Psychology, 86, 143-148. doi:10.1016/j.biopsycho.2010.02.011

Levenson, R. W. (2000). Expressive, physiological and subjective changes in emotion across adulthood. In S. H. Qualls \& N. Abeles (Eds.), Psychology and the aging revolution: How we adapt to longer life (pp. 123-140). Washington, DC: American Psychological Association. doi: 10.1037/10363-007

Levenson, R. W., Carstensen, L. L., Friesen, W. V., \& Ekman, P. (1991). Emotion, physiology, and expression in old age. Psychology and Aging, 6, 28-35. doi:10.1037/0882-7974.6.1.28

Linden, W., Earle, T. L., Gerin, W., \& Christenfeld, N. (1997). Physiological stress reactivity and recovery: Conceptual siblings separated at birth? Journal of Psychosomatic Research, 42, 117-135. doi:10.1016/ S0022-3999(96)00240-1

Mauss, I. B., Levenson, R. W., McCarter, L., Wilhelm, F. H., \& Gross, J. J. (2005). The tie that binds? Coherence among emotion experience, behavior, and physiology. Emotion, 5, 175-190. doi:10.1037/1528-3542.5 .2 .175

Mauss, I. B., \& Robinson, M. D. (2009). Measures of emotion: A review. Cognition and Emotion, 23, 209-237. doi:10.1080/02699930802204677

Neupert, S. D., Almeida, D. M., \& Charles, S. T. (2007). Age differences in reactivity to daily stressors: The role of personal control. The Journals of Gerontology: Series B: Psychological Sciences and Social Sciences, 62, P216-P225. doi:10.1093/geronb/62.4.P216

Nishime, E. O., Cole, C. R., Blackstone, E. H., Pashkow, F. J., \& Lauer, M. S. (2000). Heart rate recovery and treadmill exercise score as predictors of mortality in patients referred for exercise ECG. Journal of the American Medical Association: Journal of the American Medical Association, 284, 1392-1398. doi:10.1001/jama.284.11.1392

Plutchik, R. (1984). Emotion: A general psychoevolutionary theory. In K. R. Scherer \& P. Ekman (Eds.), Approaches to emotions (pp. 197219). Hillsdale, NJ: Erlbaum

Raudenbush, S., Bryk, A., \& Congdon, R. (2004). HLM 5: Hierarchical linear and nonlinear modeling (Version 5.64) [Computer software] Lincolnwood, IL: Scientific Software International.

Riediger, M., Schmiedek, F., Wagner, G. G., \& Lindenberger, U. (2009) Seeking pleasure and seeking pain: Differences in pro- and contrahedonic motivation from adolescence to old age. Psychological Science, 20, 1529-1535. doi:10.1111/j.1467-9280.2009.02473.x

Russell, J. A. (1980). A circumplex model of affect. Journal of Personality and Social Psychology, 39, 1161-1178. doi:10.1037/h0077714

Scheibe, S., \& Blanchard-Fields, F. (2010). Emotional aging: Recent findings and future trends. The Journals of Gerontology: Series B: Psychological Sciences and Social Sciences, 65, 135-144. doi:10.1093/ geronb/gbp132

Scherer, K. (1984). On the nature and function of emotion: A component process approach. In K. Scherer \& P. Ekman (Eds.), Approaches to emotion (pp. 293-317). Hillsdale, NJ: Erlbaum.

Seider, B. H., Shiota, M. N., Whalen, P., \& Levenson, R. W. (2011). Greater sadness reactivity in late life. Social Cognitive and Affective Neuroscience, 6, 186-194. doi:10.1093/scan/nsq069

Sheppes, G., \& Gross, J. J. (2011). Is timing everything? Temporal considerations in emotion regulation. Personality and Social Psychology Review, 15, 319-331. doi:10.1177/1088868310395778

Shiota, M. N., \& Levenson, R. W. (2012). Turn down the volume or change the channel? Emotional effects of detached versus positive reappraisal. Journal of Personality and Social Psychology, 103, 416429. doi:10.1037/a0029208

Smith, C. A., \& Lazarus, R. S. (1993). Appraisal components, core relational themes, and the emotions. Cognition and Emotion, 7, 233-269. doi:10.1080/02699939308409189

Steinhagen-Thiessen, E., \& Borchelt, M. (1999). Morbidity, medication, 
and functional limitations in very old age. In P. B. Baltes \& K. U. Mayer (Eds.), The Berlin Aging Study: Aging from 70 to 100 (pp. 131-166). Cambridge, UK: Cambridge University Press.

Steptoe, A., Dockray, S., \& Wardle, J. (2009). Positive affect and psychobiological processes relevant to health. Journal of Personality, 77, 1747-1776. doi:10.1111/j.1467-6494.2009.00599.x

Steptoe, A., Moses, J., \& Edwards, S. (1990). Age-related differences in cardiovascular reactions to mental stress tests in women. Health Psychology, 9, 18-34. doi:10.1037/0278-6133.9.1.18

Streubel, B., \& Kunzmann, U. (2011). Age differences in emotional reactions: Arousal and age-relevance count. Psychology and Aging, 26, 966-978. doi:10.1037/a0023424

Toledo, E., Pinhas, I., Aravot, D., Almog, Y., \& Akselrod, S. (2002). Functional restitution of cardiac control in heart transplant patients. American Journal of Physiology: Regulatory, Integrative and Comparative Physiology, 282, 900-908.

Uchino, B. N., Birmingham, W., \& Berg, C. A. (2010). Are older adults less or more physiologically reactive? A meta-analysis of age-related differences in cardiovascular reactivity to laboratory tasks. The Journals of Gerontology: Series B: Psychological Sciences and Social Sciences, 65, 154-162. doi:10.1093/geronb/gbp127

Uchino, B. N., Holt-Lunstad, J., Bloor, L. E., \& Campo, R. A. (2005). Aging and cardiovascular reactivity to stress: Longitudinal evidence for changes in stress reactivity. Psychology and Aging, 20, 134-143. doi: 10.1037/0882-7974.20.1.134

Uchino, B. N., Uno, D., Holt-Lunstad, J., \& Flinders, J. B. (1999). Agerelated differences in cardiovascular reactivity during acute psychological stress in men and women. The Journals of Gerontology: Series B:
Psychological Sciences and Social Sciences, 54, 339-346. doi: 10.1093/geronb/54B.6.P339

Urry, H. L., \& Gross, J. J. (2010). Emotion regulation in older age. Current Directions in Psychological Science, 19, 352-357. doi:10.1177/ 0963721410388395

von Schéele, I., von Schéele, B., Hansson, G., Winman, A., \& Theorell, T. (2005). Psychosocial factors and respiratory and cardiovascular parameters during psychophysiological stress profiling in working men and women. Applied Psychophysiology and Biofeedback, 30, 125-136. doi: 10.1007/s10484-005-4309-6

Watson, D., \& Tellegen, A. (1985). Toward a consensual structure of mood. Psychological Bulletin, 98, 219-235. doi:10.1037/0033-2909.98 .2 .219

Whitbourne, S. K. (2001). Adult development \& aging: Biopsychosocial perspectives. New York, NY: Wiley.

Wrosch, C., Miller, G. E., Lupien, S., \& Pruessner, J. C. (2008). Diurnal cortisol secretion and 2-year changes in older adults' physical symptoms: The moderating roles of negative affect and sleep. Health Psychology, 27, 685-693. doi:10.1037/0278-6133.27.6.685

Wrzus, C., Müller, V., Wagner, G. G., Lindenberger, U., \& Riediger, M. (2013). Affective and cardiovascular responding to unpleasant events from adolescence to old age: Complexity of events matters. Developmental Psychology, 49, 384-397. doi:10.1037/a0028325

Received April 7, 2013

Revision received May 15, 2014

Accepted June 10, 2014 